\title{
Effect of carbon dioxide on background cerebral electrical activity and fractional oxygen extraction in very low birth weight infants just after birth
}

\author{
SURESH VICTOR, RICHARD E. APPLETON, MARGARET BEIRNE, ANTHONY G. MARSON, AND \\ ALAN M. WEINDLING \\ Neonatal Intensive Care Unit, Liverpool Women's Hospital, Crown Street, Liverpool, UK L8 7SS. The \\ Roald Dahl EEG Unit, Department of Neurology, Royal Liverpool Children's Hospital NHS Trust (Alder \\ Hey), Eaton Road, Liverpool, UK, L12 2AP. The Roald Dahl EEG Unit, Department of Neurology, Royal \\ Liverpool Children's Hospital NHS Trust (Alder Hey), Eaton Road, Liverpool, UK, L12 2AP. Division of \\ Neurological Science, University of Liverpool, Clinical Sciences Centre, Lower Lane, Fazakerley, \\ Liverpool, UK, L9 7LJ. Division of Child Health, University of Liverpool, Neonatal Unit, Liverpool \\ Women's Hospital, Crown Street, Liverpool, UK, L8 7SS2005
}

\begin{abstract}
Decreased arterial carbon dioxide tension $\left(\mathrm{PaCO}_{2}\right)$ results in decreased cerebral blood flow, which is associated with diminished cerebral electrical activity. In such a situation, cerebral fractional oxygen extraction (CFOE) would be expected to increase to preserve cerebral oxygen delivery. This study aimed to determine whether changes in blood gases in infants less than 30 wk' gestation were associated with changes in background electroencephalograms (EEG) and CFOE. Thirty-two very low birth weight infants were studied daily for the first three days after birth. Digital EEG recordings were performed for $75 \mathrm{~min}$ each day. CFOE, mean blood pressure and arterial blood gases were measured midway through each recording. EEG was analysed by (a) spectral analysis and (b) manual calculation of interburst interval. Blood pressure, $\mathrm{pH}$ and $\mathrm{PaCO}_{2}$ did not have any effect on the EEG. On day one, only $\mathrm{PaCO}_{2}$ showed a relationship with the relative power of the delta frequency band $(0.5-3.5 \mathrm{~Hz})$ and the interburst interval. The relative power of the delta band
\end{abstract}

\section{ABSTRACT}

remained within normal limits when $\mathrm{PaCO}_{2}$ was between 24 and $55 \mathrm{~mm} \mathrm{Hg}$ on day one. There was a negative association between $\mathrm{PaCO}_{2}$ and CFOE. The associations between $\mathrm{PaCO}_{2}$ and EEG measurements were strongest on day one, weaker on day two, and absent on day three. The slowing of EEG and increased CFOE at lower levels of $\mathrm{PaCO}_{2}$ are likely to be due to decreased cerebral oxygen delivery induced by hypocarbia. When $\mathrm{PaCO}_{2}$ was higher, there was suppression of the EEG. (Pediatr Res 58: 579-585, 2005)

\begin{tabular}{l}
\multicolumn{1}{c}{ Abbreviations } \\
$\mathrm{PaCO}_{2}$, arterial carbon dioxide \\
$\mathrm{CFOE}$, cerebral fractional oxygen extraction \\
$\mathrm{CSvO}_{2}$, cerebral venous oxygen saturation \\
$\mathrm{CSaO}_{2}$, cerebral arterial oxygen saturation \\
$\mathbf{P}_{\mathbf{9 0}}, 90^{\text {th }}$ centile
\end{tabular}

Periventricular leukomalacia is an important cause of neurologic morbidity in very low birth weight infants (1) and has been associated with severe hypocarbia during the first $24 \mathrm{~h}$ after birth. This effect of arterial carbon dioxide tension $\left(\mathrm{PaCO}_{2}\right)$ on the brain is likely to be mediated through its effect on cerebral blood flow, which is decreased by hypocarbia. In such a situation, cerebral fractional oxygen extraction (CFOE) would be expected to increase, as cerebral oxygen delivery is reduced (8). Decreased cerebral oxygen delivery would also be

Received February 18, 2004; accepted November 16, 2004.

Correspondence: Suresh Victor, MBBS, MRCPCH, Neonatal Intensive Care Unit, Liverpool Women's Hospital, Crown Street, Liverpool, UK L8 7SS. Tel: 0044151702 4171, Fax: 0044151702 4313; email: svictor@liverpool.ac.uk

This work was supported by the Newborn Appeal.

DOI: $10.1203 / 01 . p d r .0000169402 .13435 .09$ expected to be associated with reduced cerebral electrical activity. A positive relationship between cerebral blood flow and integrated amplitude of the EEG has been demonstrated on a group of infants between 27 and 33 wk' gestation (9). However, no studies have described the relationship between background cerebral electrical activity and $\mathrm{PaCO}_{2}$ in very low birth weight infants.

Electroencephalography provides a noninvasive technique for monitoring cerebral electrical activity. The normal EEG pattern of infants less than 30 wk' gestation is markedly discontinuous and consists of long isoelectric periods called interburst intervals, interspersed with bursts of high voltage and mixed frequency activity (10). Two separate studies have linked adverse neurologic outcome of such infants with an abnormal background EEG activity characterised by prolonged 
interburst intervals $(11,12)$. When the interburst interval was longer than $30 \mathrm{~s}$ in premature newborns less than $28 \mathrm{wk}$ ' gestation and longer than $25 \mathrm{~s}$ in infants above 28 wk' gestation, death and developmental motor abnormalities including mild distal hypertonia and spastic diplegia or tetraplegia were observed more frequently (12). Measuring interburst intervals therefore appears to be a useful method of quantifying EEG in infants less than $30 \mathrm{wk}$ ' gestation. However, if it has to be done manually, the process is time consuming.

An automatic method for quantifying the EEG is by spectral analysis based on the principle of Fast Fourier Transformation. The results of this approach for premature infants less than 30 wk' gestation during the first four days after birth has been previously described (13). When the EEG spectrum was divided into delta $(0.5-3.5 \mathrm{~Hz})$, theta $(4-7.5 \mathrm{~Hz})$, alpha $(8-12.5$ $\mathrm{Hz})$ and beta $(13-30 \mathrm{~Hz})$ frequency bands, the relative power of the delta band appeared to be best for the quantitative analysis of the EEG of these very premature infants (13). The coefficient of repeatability $(8 \%)$ of the relative power of the delta frequency band was acceptably low (13). The normal range of the relative power of the delta band was between $62 \%$ and $76 \%(n=22)$ on the first day after birth, and between $65 \%$ and $82 \%(n=28)$ on the second day after birth (13). This present study describes the relationship between EEG spectral analysis and arterial blood gases.

The purpose of this study was to determine the relationship between cerebral electrical activity, the balance between cerebral oxygen delivery and utilisation as measured by CFOE, mean blood pressure and arterial blood gases in newborn very low birth weight infants less than 30 wk' gestation.

\section{METHODS}

This was a prospective observational study performed on infants born at Liverpool Women's Hospital with birth weight less than $1500 \mathrm{~g}$ and gestation less than $30 \mathrm{wk}$. Ethical approval was obtained from the Local Research Ethics Committee and informed parental consent was obtained. The upper limit of 30 wk' gestation was chosen, as sleep wake cycling is typically not seen below this gestation $(14,15)$. Infants with significant intra-ventricular haemorrhages (defined as haemorrhages extending beyond the germinal matrix) have abnormally prolonged periods of EEG discontinuity and were therefore also excluded (11).

Electroencephalography (EEG). Digital EEG and electrocardiography recordings were performed for $75 \mathrm{~min}$ using a Micromed 16-channel system on each of the first three days after birth. Six electrodes were placed on the frontal (Fp1, Fp2), central (C3, C4) and occipital (O1, O2) positions bilaterally according to the International 10-20 System (16). A reference electrode was placed at the vertex $(\mathrm{Cz})$. Skin impedance of less than $2 \mathrm{k} \Omega$ was maintained for all recordings. A sampling rate of $256 \mathrm{~Hz}$ was used for digitisation.

The EEG was analysed by a qualitative approach as well as by quantitative methodology. MB and RA experienced at reporting EEGs did the qualitative reporting. They were blinded to $\mathrm{PaCO}_{2}, \mathrm{PaO}_{2}, \mathrm{pH}$ and cranial ultrasound findings and the results of the quantitative analysis of the EEG (see below). During reporting, the EEG was viewed as four bipolar channels (Fp1-C3, C3-O1, Fp2-C4 and C4-O2) using a high pass filter of $0.3 \mathrm{~Hz}$, a low pass filter of $70 \mathrm{~Hz}$, a notch filter of $50 \mathrm{~Hz}$, a base time of $10 \mathrm{~s}$ and a gain of $100 \mu \mathrm{V}$. Reports described discontinuity, abnormal transients, asymmetry and asynchrony.

Quantitative analysis of EEG was by (a) spectral analysis and (b) manual calculation of the interburst interval. To calculate the interburst intervals, gross artefacts (activity with no identifiable normal EEG activity) were identified by eye and removed. The interburst interval was defined as a period between electrical bursts during which activities were lower than $30 \mu \mathrm{V}$ in all leads and calculated manually (17). The $90^{\text {th }}$ centile for interburst interval $\left(\mathrm{P}_{90}\right)$ was then calculated for the first 60-min of artefact free recording.
Spectral analysis using Fast Fourier transformation was performed using the manufacturer's software (Micromed). The $75 \mathrm{~min}$ of EEG was subjected to spectral analysis. The spectrum was sub-divided into delta $(0.5-3.5 \mathrm{~Hz})$, theta $(4-7.5 \mathrm{~Hz})$, alpha $(8-12.5 \mathrm{~Hz})$ and beta $(13-30 \mathrm{~Hz})$ bands. The absolute power of a band was defined as the integral of all the power values over the frequency range and expressed as $\mu \mathrm{V}^{2}$ (Fig. 1). The relative power (RP) of a frequency band was defined as the ratio of the absolute power of that frequency band to the total power of all frequency bands and expressed as a percentage (Fig. 1). The absolute and relative powers of each band were calculated for every 10-s epoch. Gross artefacts (activity with no identifiable normal EEG activity) were identified by eye and removed manually in 10 -s epochs. The first $60 \mathrm{~min}$ of artefact free EEG was then used to calculate the median absolute and the median relative powers of each band.

Cerebral fractional oxygen extraction (CFOE). Measurements were made during an EEG recording. The Hamamatsu NIRO 500 and a pulse oximeter in beat-to-beat mode (Datex-Ohmeda) with partial jugular venous occlusion was used to measure cerebral venous oxygen saturation $\left(\mathrm{CSvO}_{2}\right)$. The $\mathrm{CSvO}_{2}$ value was the mean of five partial jugular venous occlusions made over a 5 to $10 \mathrm{~min}$ period and selected using preset criteria $(8,18)$. Cerebral arterial oxygen saturation $\left(\mathrm{CSaO}_{2}\right)$ was assumed to be equal to peripheral arterial oxygen saturation. $\mathrm{CFOE}$ was calculated using the formula: $\mathrm{CFOE}=\mathrm{CSaO}_{2}-\mathrm{CSvO}_{2} /$ $\mathrm{CSaO}_{2}(8,18)$.

To determine the intraobserver repeatability of CFOE measurements, studies were conducted on a group of ten infants with median gestation of $27 \mathrm{wk}$ (range: 24-30) and median birth weight of $970 \mathrm{~g}$ (range: 575-1410). Two CFOE measurements (each a mean of five occlusions) were made on each baby five minutes apart. The optodes were removed and replaced between measurements. The coefficient of repeatability was calculated by plotting the differences between pairs of measurements against the mean: twice the SD of the differences gave the coefficient of repeatability (19).

Other measurements. Mean blood pressure, arterial blood gas and acid base status were measured midway through an EEG recording using indwelling arterial catheters. Cranial ultrasound scans were performed every day for the first three days after birth. Follow-up cranial ultrasound scans were performed usually weekly for clinical purposes until discharge from the neonatal unit. The images from these scans were examined for periventricular leukomalacia.

Clinical management. The clinical management of the babies in this study was according to clinical guidelines and by clinicians who were not members of the research group. The general aim was to keep the $\mathrm{PaCO}_{2}$ between 35 and $45 \mathrm{~mm} \mathrm{Hg}$.

Statistical analysis. Measurements and recordings from each day were analysed separately. Statistical analysis was by stepwise linear regression using SPSS. Gestation, $\mathrm{PaCO}_{2}, \mathrm{pH}, \mathrm{PaO}_{2}$, mean blood pressure and age of recording were entered as predictor variables. The relative power and absolute power of each frequency band (delta, theta, alpha and beta), $\mathrm{P}_{90}$ interburst interval and CFOE were entered individually as outcome variables. Curve estimation was done to check for the best fit in every statistically significant linear regression model. A normal probability plot was also examined to ensure that the assumptions for linear regression were satisfied.

\section{RESULTS}

Thirty-two infants with demography as described in Table 1 were studied on the first three days after birth. All had com-

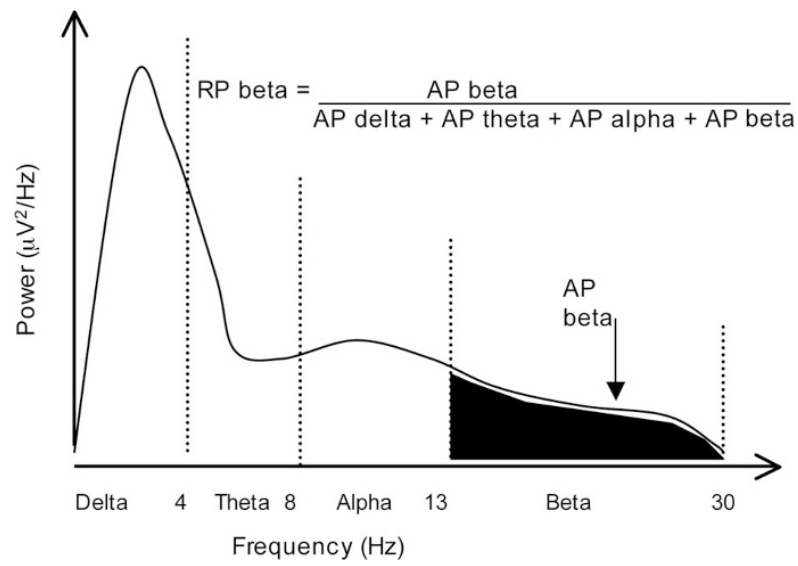

Figure 1. Spectral density display showing calculation of the relative power (RP) and absolute power (AP). Calculation of the AP and RP of the beta frequency band has been shown as an example. 
plete EEG recordings. There were CFOE results for 22 babies on each day. Thirty CFOE measurements were missed due to equipment failure. All infants had normal blood glucose concentrations at the time of recording. The conditions of infants during recording were as described in Table 2. Follow up cranial ultrasound scans showed no evidence of cystic periventricular leukomalacia or intraventricular haemorrhage in any of the infants.

The coefficient of repeatability (19) for CFOE measurements was 0.05 . That is, $95 \%$ of repeated measurements of CFOE would be expected to be within \pm 0.05 of the first measurement. As the mean (SD) of the repeated measurements $(n=$ 20) was $0.29(0.07)$, a difference of \pm 0.05 (17\% of the mean) suggests good repeatability.

When the qualitative analysis of the unprocessed EEG was considered, the following changes were noted in relation to $\mathrm{PaCO}_{2}$. On the first and second day after birth, lower levels of $\mathrm{PaCO}_{2}$ were associated with attenuation of fast frequency activities and the presence of slow waves without brushes or bursts or other rhythmic high frequency activities (Trace 1 of Fig. 2). At higher levels of $\mathrm{PaCO}_{2}$ there were prolonged interburst intervals and suppression of EEG (Trace 3 of Fig. 2). Two-thirds of the recording consisted of discontinuous periods when $\mathrm{PaCO}_{2}$ levels increased above $55 \mathrm{~mm} \mathrm{Hg}$. These changes were not seen on the third day.

The EEG changes in relation to $\mathrm{PaCO}_{2}$ were also quantified using spectral analysis and measurement of interburst intervals and the results were as shown in Table 3. Using stepwise linear regression, only $\mathrm{PaCO}_{2}$ from amongst the predictor variables showed a relationship to EEG measurements (Table 3). There were no significant relationships between mean blood pressure, $\mathrm{pH}, \mathrm{PaO}_{2}$ and $\mathrm{PaCO}_{2}$ and the relative powers of theta and alpha bands and the absolute powers of all bands. The association between $\mathrm{PaCO}_{2}$, EEG measurements and $\mathrm{CFOE}$ was stronger on day one than on day two (Tables 3). No statistically significant models were obtained on day three. The relationships between $\mathrm{PaCO}_{2}$ and the relative power of the delta band and beta bands, $\mathrm{P}_{90}$ interburst interval and CFOE on day one were as shown in Figs. 3-5.

We were interested to discover the pattern of the relationship between blood gases, the EEG and CFOE. Curve estimation indicated that a cubic regression model $(\mathrm{Rsq}=0.59 ; p<$ 0.001) was a better fit for the relationship between $\mathrm{P}_{90}$ interburst interval and $\mathrm{PaCO}_{2}$ on day one than a linear model (Rsq $=0.51 ; p<0.001$ ) (Fig. 4). The relative powers of the delta and beta bands showed a linear relationship to $\mathrm{PaCO}_{2}$ as best fit (Figs. 3 and 5). Hence, at lower levels of $\mathrm{PaCO}_{2}$ (for the ranges studied) there was an increase in the relative power of the delta band without much change in the interburst interval.

Table 1. Demography of cohort studied $(n=32)$

\begin{tabular}{lc}
\hline Characteristics & Median (range) \\
\hline Gestation (wks) & $27(24-30)$ \\
Male:Female & $17: 13$ \\
Birth weight $(\mathrm{g})$ & $935(528-1490)$ \\
5 minute Apgar & $8(5-10)$ \\
Cord base excess & $-1.9(+1.3$ to -9.6$)$ \\
\hline
\end{tabular}

Table 2. Median (range) of acid base, blood pressure and ventilatory status for each day of recording

\begin{tabular}{lccc}
\hline Characteristics & $\begin{array}{c}\text { Day } 1 \\
(n=32)\end{array}$ & $\begin{array}{c}\text { Day 2 } \\
(n=32)\end{array}$ & $\begin{array}{c}\text { Day 3 } \\
(n=32)\end{array}$ \\
\hline Age (hours) & $11(4-16)$ & $31(24-46)$ & $54(48-70)$ \\
$\mathrm{PaO}_{2}(\mathrm{~mm} \mathrm{Hg})$ & $59(40-143)$ & $54(40-156)$ & $53(40-106)$ \\
$\mathrm{Arterial} \mathrm{pH}$ & $7.3(7.2-7.5)$ & $7.3(7.2-7.4)$ & $7.3(7.1-7.5)$ \\
$\mathrm{PaCO}_{2}(\mathrm{~mm} \mathrm{Hg})$ & $39(24-58)$ & $43(24-58)$ & $40(24-70)$ \\
$\mathrm{Mean} \mathrm{BP}(\mathrm{mm} \mathrm{Hg})$ & $34(23-52)$ & $41(26-51)$ & $44(35-53)$ \\
$\mathrm{MAP}\left(\mathrm{cms} \mathrm{of} \mathrm{H}_{2} \mathrm{O}\right)$ & $7(4-16)$ & $5(0-11)$ & $5(0-13)$ \\
\hline
\end{tabular}

MAP, mean airway pressure; BP, blood pressure.
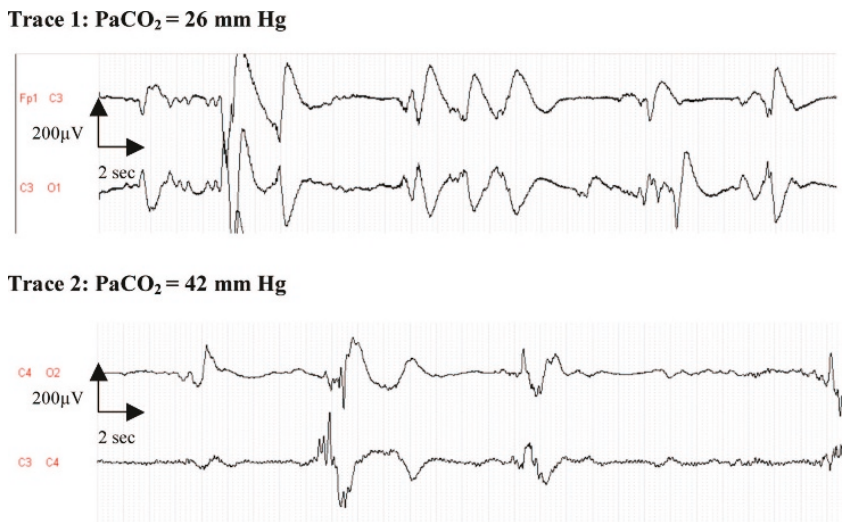

Trace 3: $\mathrm{PaCO}_{2}=58 \mathrm{~mm} \mathrm{Hg}$

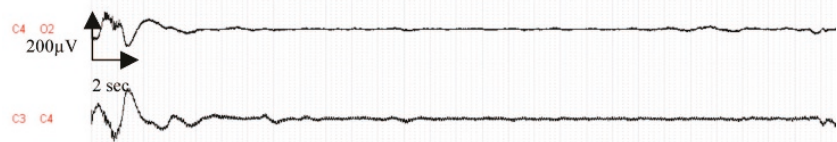

Figure 2. Examples of EEG trace showing changes in relation to $\mathrm{PaCO}_{2}$. Traces were recorded from three different infants of $26-27$ wk' gestation on the first day after birth

Table 3. Relationship by stepwise linear regression and Pearson's correlation on the first day of birth

\begin{tabular}{|c|c|c|c|c|c|c|}
\hline \multirow[t]{2}{*}{ Outcome } & \multicolumn{3}{|c|}{ Day one } & \multicolumn{3}{|c|}{ Day two } \\
\hline & $n$ & $\begin{array}{l}\text { Slope } \\
\text { (beta) }\end{array}$ & $p$ value & $n$ & $\begin{array}{l}\text { Slope } \\
\text { (beta) }\end{array}$ & $p$ value \\
\hline RP of delta band & 32 & -0.67 & $<0.001$ & 32 & -0.4 & 0.023 \\
\hline $\mathrm{RP}$ of beta band & 32 & 0.5 & 0.004 & 32 & $0.33 \dagger$ & 0.69 \\
\hline $\mathrm{P}_{90}$ IBI & 32 & 0.71 & $<0.001$ & 32 & 0.51 & 0.006 \\
\hline CFOE & 22 & -0.47 & 0.004 & 22 & $-0.23 \dagger$ & 0.29 \\
\hline
\end{tabular}

* There were no significant relationships between $\mathrm{PaCO} 2$ and the relative powers of theta and alpha bands and the absolute powers of all bands).

$\dagger$ Pearsons correlation was used as there were no statistically significant regression models.

However, at higher levels of $\mathrm{PaCO}_{2}$, the relative power of the delta band decreased with dramatic increases in interburst interval.

The relationships were explored between $\mathrm{PaCO}_{2}$ and the relative power of the delta band and $\mathrm{P}_{90}$ interburst interval. The relative power of the delta band decreased below its lower normal limit of $62 \%$ on day one when $\mathrm{PaCO}_{2}$ was more than 55 $\mathrm{mm} \mathrm{Hg}$ and reached its upper normal limit of $76 \%$ when $\mathrm{PaCO}_{2}$ was $24 \mathrm{~mm} \mathrm{Hg}$. The $\mathrm{P}_{90}$ interburst interval remained within normal limits on the first day of recording at low levels 
A

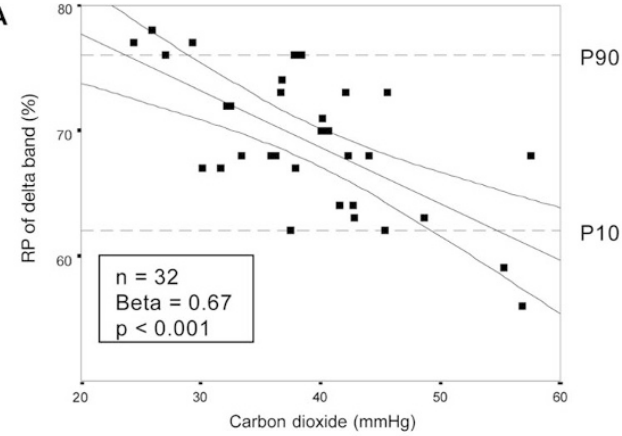

B

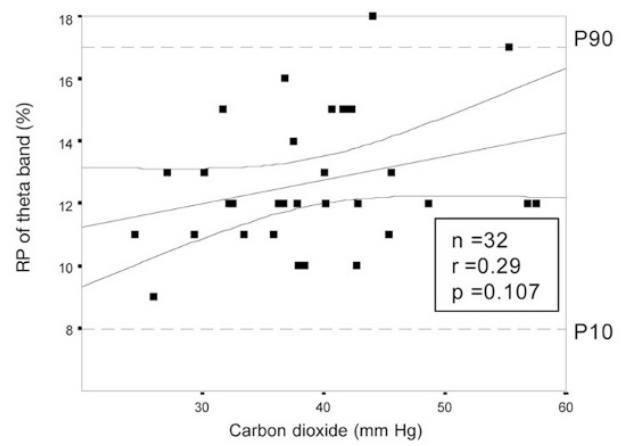

C
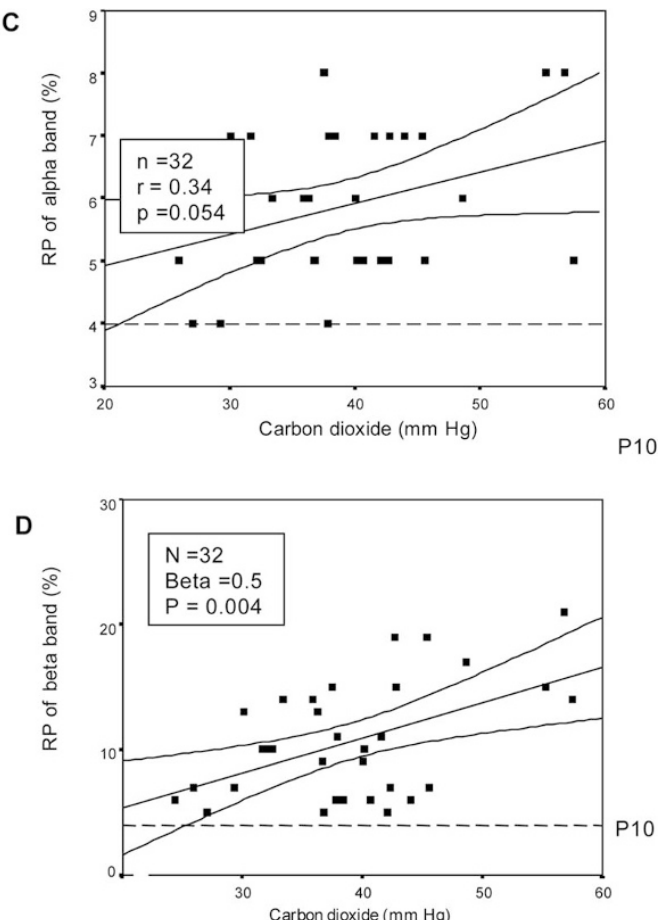

Figure 3. Relationship between $\mathrm{PaCO}_{2}$ and the relative power (RP) of all EEG frequency bands on day one, showing the regression line of best fit with 95\% confidence interval. The dotted lines indicate normal ranges of the relative power of the frequency bands $\left(10^{\text {th }}-90^{\text {th }}\right.$ centile $)$. A. PaCO 2 and the relative power (RP) of the EEG delta frequency band $\mathrm{B}$. $\mathrm{PaCO}_{2}$ and the relative power (RP) of the EEG theta frequency band. $\mathrm{C}$. PaCO $\mathrm{C}_{2}$ and the relative power (RP) of the EEG alpha frequency band $\mathrm{D} . \mathrm{PaCO}_{2}$ and the relative power (RP) of the EEG beta frequency band.

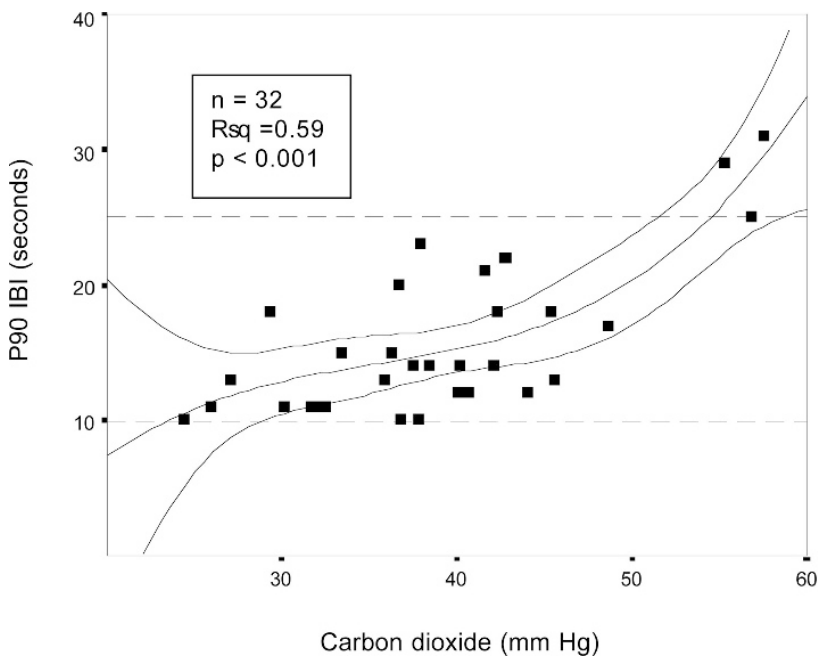

Figure 4. Best fit relationship between $\mathrm{PaCO}_{2}$ and $\mathrm{P}_{90}$ interburst interval (IBI) on day one using cubic regression model with $95 \%$ confidence intervals. The dotted lines indicate the normal range of the $\mathrm{P}_{90}$ interburst interval $\left(10^{\text {th }}-90^{\text {th }}\right.$ centile)

of $\mathrm{PaCO}_{2}$ and exceeded the upper limits when $\mathrm{PaCO}_{2}$ was more than $55 \mathrm{~mm} \mathrm{Hg}$. The relative power of the delta band and $\mathrm{P}_{90}$ interburst interval remained within normal limits on day two despite a significant relationship with $\mathrm{PaCO}_{2}$.

\section{DISCUSSION}

Changes in background cerebral electrical activity have been observed in association with changes in $\mathrm{PaCO}_{2}$ during the first three days after birth in very low birth weight infants. $\mathrm{PaCO}_{2}$ appears to have an important effect on cerebral electrical

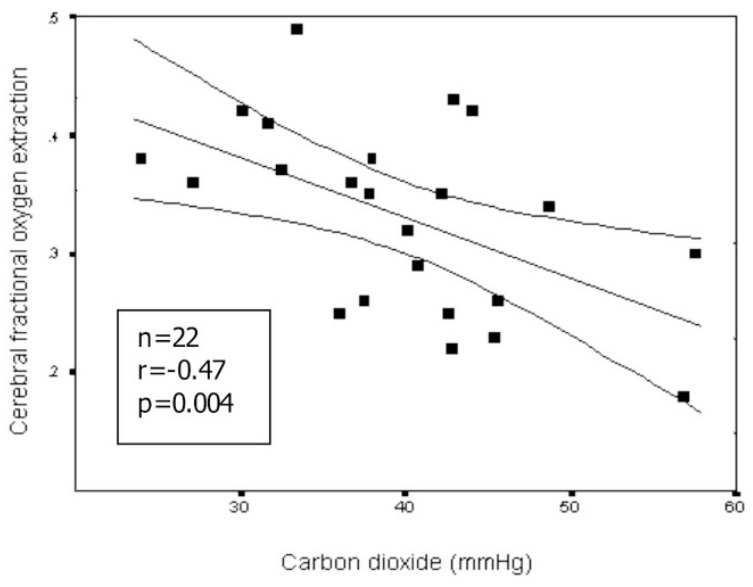

Figure 5. Best fit relationship between $\mathrm{PaCO}_{2}$ and CFOE on day one with $95 \%$ confidence intervals.

activity and fractional oxygen extraction in very immature infants during the first days after birth. The effect was greatest on the first day, diminished progressively and was no longer apparent on day three.

Lower levels of $\mathrm{PaCO}_{2}$ were associated with increased CFOE and slowing of the EEG while higher levels of $\mathrm{PaCO}_{2}$ were associated with EEG signal suppression. With hypocarbia there was an increase in the relative power of the delta band and a decrease in the relative powers of the beta and alpha bands, suggested slowing of the EEG. This was confirmed by visual inspection of the unprocessed EEG which showed slowing that was manifested as smooth slow waves sometimes called delta waves with attenuated fast frequency activity (Trace 1 of Fig. 2). Hypercarbia was associated with prolonged 
interburst intervals, suggesting suppression of EEG. This was shown by both quantitative analysis of the artefact free EEG trace and visual inspection of the unprocessed trace (Trace 3 of Fig. 2). The reasons for the EEG changes seen in these very immature infants are likely to be different for hypo- and hypercarbia. In this discussion the possible mechanisms for each condition and the implications for clinical practice are explored followed by a critique on the methodology used.

The slowing of EEG and increased CFOE observed at lower levels of $\mathrm{PaCO}_{2}$ is likely to be the result of decreased cerebral oxygen delivery induced by hypocarbia. Hypocarbia reduces cerebral oxygen delivery (a) by cerebral vasoconstriction resulting in decreased cerebral blood flow $(5-7,20,21)$ and (b) by decreasing oxy-haemoglobin dissociation resulting in decreased oxygen availability (22). The EEG changes observed at lower levels of $\mathrm{PaCO}_{2}$ were similar to those described in relation to hypoxaemia by Roberton (1969) (23). He observed that the newborn premature infant's brain responded to hypoxaemia in a manner similar to that of the adult human with an initial slowing of electrical activity followed by electrical silence (23). Similar EEG changes, characterised by diffuse and reversible slowing were observed in response to hyperventilation in children $(24,25)$. Although Gotoh et al. (1965) considered that the slowing of EEG in this situation was a direct result of cerebral ischaemic anoxia resulting from hypocapnic cerebral vasoconstriction (26), it is more likely, as others have proposed, that these EEG changes were caused by decreased cerebral oxygen delivery (27). In a group of preterm infants below 33 wk' gestation, visual evoked potentials to flash stimuli were normal at $\mathrm{PaCO}_{2}$ levels between 17 and 48 $\mathrm{mm} \mathrm{Hg} \mathrm{(28),} \mathrm{but} \mathrm{such} \mathrm{responses} \mathrm{may} \mathrm{not} \mathrm{represent} \mathrm{general}$ cortical activity and can be elicited at the ocular end of the neural pathway between the eye and the visual cortex (29).

Further evidence that slowing of the EEG is caused by decreased cerebral oxygen delivery induced by hypocarbia is given by the associated increase in CFOE observed at lower levels of $\mathrm{PaCO}_{2}$ in both this and previous studies $(8,30)$. Studies on newborn lambs have also demonstrated a strong negative correlation between $\mathrm{CFOE}$ and $\mathrm{PaCO}_{2}$ (31). As previously $(8,30)$, blood pressure was found to have no effect on CFOE.

The EEG changes and the increase in CFOE would be appropriate responses to reduced cerebral oxygen delivery caused by hypocarbia. The slowing of the EEG, which results in decreased oxygen consumption, is likely to be an adaptive response to decreased cerebral oxygen delivery. The mechanisms by which this may occur include (a) depolarisation of neurones by an increased extracellular potassium concentration due to lactic acidosis resulting from decreased cerebral oxygen delivery $(31,32)$, and (b) blockage of presynaptic calcium channels by adenosine which increases as ATP is consumed in excess of production (32).

The limit of $\mathrm{PaCO}_{2}$ below which cerebral damage may occur is of interest to clinicians, but the present study gives no answer. The EEG changes of slowing with attenuated fast frequency activities noted in relation to hypocarbia are not invariably associated with an adverse neurologic outcome. Watanabe et al. described normal neurodevelopment in $89 \%$ of preterm infants when there was attenuated fast frequency activity (33). Furthermore, only severe hypocarbia (less than $20 \mathrm{~mm} \mathrm{Hg}$ ) has been previously associated with periventricular leukomalacia (2-4) - in the present study the lowest observed $\mathrm{PaCO}_{2}$ was $24 \mathrm{~mm} \mathrm{Hg}$ and none of the infants developed cystic periventricular leukomalacia. Nevertheless, attenuation of fast frequency activity in EEGs of premature infants should alert clinicians and neurophysiologists to the possibility of decreased cerebral oxygen delivery and the dangers of hypocarbia.

Higher levels of $\mathrm{PaCO}_{2}$ were associated with suppression of EEG. Suppression of EEG with hypercarbia and normal blood oxygen levels has been demonstrated in animals and adult humans (34-36). In rats with isolated increases in $\mathrm{PaCO}_{2}$ and normoxemia, the amplitude of EEG also decreased progressively as $\mathrm{PaCO}_{2}$ increased (36). In these studies, low frequency waves were initially reduced in amplitude followed by those of high frequency.

The observed effect of hypercarbia on the EEG in this present study might be due to changes in membrane permeability of cortical cells induced by hydrogen ions. In rats, there was hyperpolarisation of the membrane potential of cortical nerve cells when the $\mathrm{PaCO}_{2}$ level was increased (36), demonstrating that such a hyperpolarisation was caused primarily by a reduction of excitatory postsynaptic potential. The disappearance of EEG activity may be caused mainly by reduced excitatory postsynaptic activity.

Hypercarbia increases oxyhaemoglobin dissociation resulting in increased oxygen availability at the cellular level with the reverse occurring during hypocarbia (22). Hypercarbia also causes cerebral vasodilatation (37) resulting in increased cerebral blood flow and oxygen delivery $(38,39)$. CFOE is therefore expected to fall with increasing $\mathrm{PaCO}_{2}$-an association observed in both the present study and a previous study on newborn lambs (40).

Although prolonged interburst intervals have been associated with adverse neurologic outcome $(11,12)$ it is more likely that the prolonged interburst interval associated with high $\mathrm{PaCO}_{2}$ is reversible. Such reversibility has been demonstrated in the preterm human and animal studies $(35,41)$. Nevertheless, levels of $\mathrm{PaCO}_{2}$ above $55 \mathrm{~mm} \mathrm{Hg}$ on the first day after birth appear to be associated with carbon dioxide induced narcosis (42) and $\mathrm{PaCO}_{2}$ to be taken into account when interpreting the EEG of premature newborn infants and assessing their neurologic status.

In this study, the effect of $\mathrm{PaCO}_{2}$ on the EEG and CFOE was detected only on the first two days after birth, and not on the third. Furthermore, the effect of $\mathrm{PaCO}_{2}$ was stronger on day one than on day two. These observations have to be explained in the light of what is known about cerebral haemodynamics in the very low birthweight infants during the immediate postnatal period. There is evidence that cerebral oxygen delivery increases during the days after birth: CFOE decreases (30) and there are increases in cardiac output (43), systemic blood pressure (44) and cerebral blood flow (45). These observations suggest that the infant is particularly vulnerable to decreased cerebral oxygen delivery on the first day after birth. 
Several studies have shown that cerebral vasoreactivity to changing $\mathrm{PaCO}_{2}$ increases with postnatal age (46-48). At first sight, this observation would appear to be out of line with the results of the present study. However, this study did not investigate cerebral vasoreactivity directly. On day one, when cerebral perfusion was the lowest, the effects of $\mathrm{PaCO}_{2}$ on the EEG and on CFOE were most marked. However, on subsequent days, it is likely that cerebral perfusion improved and, despite increased cerebral vasoreactivity, cerebral electrical activity was maintained.

The effect of $\mathrm{PaCO}_{2}$ on the cerebral vasculature is likely to be mediated through the alteration of intracerebral $\mathrm{pH}(49,50)$. However, no relationship between blood $\mathrm{pH}$ and the EEG was detected in this study. As $\mathrm{PaCO}_{2}$ diffuses more rapidly through the blood brain barrier than hydrogen ions, $\mathrm{PaCO}_{2}$ may have more of an effect on cerebral function than $\mathrm{pH}$ (51). Prolonged periods of EEG discontinuity have been associated with changes in $\mathrm{pH}$, in a group of preterm infants between 24 and 32 wk' gestation with metabolic and respiratory acidosis (41). However, even in that study, in infants with respiratory acidosis and continuous transcutaneous carbon dioxide monitoring, the onset of increase in EEG discontinuity closely mirrored the increase in carbon dioxide (41). There was no demonstrable effect on the EEG due to $\mathrm{PaO}_{2}$. However, the lowest level of $\mathrm{PaO}_{2}$ studied was $40 \mathrm{~mm} \mathrm{Hg}$ and a study on premature babies showed that EEG changes occurred only at levels below 40 $\mathrm{mm} \mathrm{Hg} \mathrm{(23).}$

In conclusion, lower levels of $\mathrm{PaCO}_{2}$ were associated with slowing of EEG and increased CFOE. These observations make it likely that the observed change was because of decreased cerebral oxygen delivery caused by vasoconstriction due to hypocarbia. At higher levels of $\mathrm{PaCO}_{2}$ there was suppression of EEG.

\section{REFERENCES}

1. Weindling AM, Rochefort MJ, Calvert SA, Fok TF, Wilkinson A 1985 Development of cerebral palsy after ultrasonographic detection of periventricular cysts in the newborn. Dev Med Child Neurol ;27:800-806

2. Fujimoto S, Togari H, Yamaguchi N, Mizutani F, Suzuki S, Sobajima H 1994 Hypocarbia and cystic periventricular leukomalacia in premature infants. Arch Dis Child 71:F107-F110

3. Greisen G, Munck H, Lou H 1987 Severe hypocarbia in preterm infants and neurodevelopmental deficit. Acta Paediatr Scand 76:401-404

4. Wiswell TE, Graziani LJ, Kornhauser MS, Stanley C, Merton DA, McKee L, Spitzer AR 1996 Effects of hypocarbia on the development of cystic periventricular leukomalacia in premature infants treated with high-frequency jet ventilation. Pediatrics 98:918-924

5. Gleason CA, Short BL, Jones MD Jr 1989 Cerebral blood flow and metabolism during and after prolonged hypocapnia in newborn lambs. J Pediatr 115:309-314

6. Rosenberg AA 1992 Response of the cerebral circulation to hypocarbia in postasphyxia newborn lambs Pediatr Res 32:537-541

7. Whitelaw A, Karlsson BR, Haaland K, Dahlin I, Steen PA, Thoresen M 1991 Hypocapnia and cerebral ischaemia in hypotensive newborn piglets. Arch Dis Child 66:1110-1114

8. Wardle SP, Yoxall CW, Weindling AM 2000 Determinants of cerebral fractional oxygen extraction using near infrared spectroscopy in preterm neonates. J Cereb Blood Flow Metab 20:272-279

9. Greisen G, Pryds O 1989 Low CBF, discontinuous EEG activity, and periventricular brain injury in ill, preterm neonates. Brain Dev 11:164-168

10. Scher MS 1999 Electroencephalography of the newborn: normal and abnormal features. In: Niedermeyer E, Da Silva FL (eds) Electroencephalography: Basic Principles, Clinical Applications, and Related Fields. Williams and Wilkins, Baltimore, pp 896-946

11. Benda GI, Engel RC, Zhang YP 1989 Prolonged inactive phases during the discontinuous pattern of prematurity in the electroencephalogram of very-low-birthweight infants. Electroencephalogr Clin Neurophysiol 72:189-197
12. Marret S, Parain D, Menard JF, Blanc T, Devaux AM, Ensel P, Fessard C, SamsonDollfus D 1997 Prognostic value of neonatal electroencephalography in premature newborns less than 33 weeks of gestational age. Electroencephalogr Clin Neurophysiol 102:178-185

13. Victor S, Appleton RE, Beirne M, Marson AG, Weindling AM. Spectral analysis of electroencephalography in premature newborn infants: normal ranges. Pediatr Res (In press)

14. Watanabe K, Iwase K, Hara K 1973 Heart rate variability during sleep and wakefulness in low-birthweight infants. Biol Neonate 22:87-98

15. Parmelee AH Jr., Wenner WH, Akiyama Y, Schultz M, Stern E 1967 Sleep states in premature infants. Dev Med Child Neurol 9:70-77

16. Jasper HH 1958 The Ten - Twenty electrode system of the international federation. Electroencephalogr Clin Neurophysiol 10:371-375

17. Biagioni E, Bartalena L, Biver P, Pieri R, Cioni G 1996 Electroencephalographic dysmaturity in preterm infants: a prognostic tool in the early postnatal period. Neuropediatrics 27:311-316

18. Yoxall CW, Weindling AM, Dawani NH, Peart I 1995 Measurement of cerebral venous oxyhemoglobin saturation in children by near-infrared spectroscopy and partial jugular venous occlusion. Pediatr Res 38:319-323

19. Bland JM, Altman DG 1986 Statistical methods for assessing agreement between two methods of clinical measurement. Lancet 1:307-310

20. Muizelaar JP, van der Poel HG, Li ZC, Kontos HA, Levasseur JE 1988 Pial arteriolar vessel diameter and $\mathrm{CO} 2$ reactivity during prolonged hyperventilation in the rabbit. J Neurosurg 69:923-927

21. Sadoshima S, Fujishima M, Tamaki K, Nakatomi Y, Ishitsuka T, Ogata J, Omae T 1980 Response of cortical and pial arteries to changes in arterial CO2 tension in rats-a morphometric study. Brain Res 189:115-120

22. Bohr C, Hasselbach K, Krog A 1904 Über einer in biologischer Beziehung wichtigen Einfluss, den die Kohlensäurespannung des Blutes auf dessen Sauerstoffbindung übt. Skand Arch Physiol 16:402-412

23. Roberton N. 1969 Effect of acute hypoxia on blood pressure and electroencephalogram of newborn babies. Arch Dis Child 44:719-725

24. Takahashi T 1999 Activation methods. In: Niedermeyer E, Da Silva FL (eds) Electroencephalography: Basic Principles, Clinical Applications, and Related Fields. Williams and Wilkins, Baltimore, pp 261-284

25. Yamatani M, Konishi T, Murakami M, Okuda T 1995 Hyperventilation activation on EEG recording in children with epilepsy. Pediatr Neurol 13:42-45

26. Gotoh F, Meyer JS, Takagi Y 1965 Cerebral effects of hyperventilation in man. Arch Neurol 12:410-423

27. Hoshi Y, Okuhara H, Nakane S, Hayakawa K, Kobayashi N, Kajii N 1999 Reevaluation of the hypoxia theory as the mechanism of hyperventilation-induced EEG slowing. Pediatr Neurol 21:638-643

28. Greisen G, Trojaborg W 1987 Cerebral blood flow, PaCO2 changes, and visual evoked potentials in mechanically ventilated, preterm infants. Acta Pediatr Scand 76:394-400

29. Atkinson J, Anker S, Rae S, Weeks F, Braddick O, Rennie J 2002 Cortical visual evoked potentials in very low birth weight premature infants. Arch Dis Child Fetal Neonatal Ed 86:F28-F31

30. Kissack CM, Garr R, Wardle SP, Weindling AM 2004 Cerebral fractional oxygen extraction in very low birth weight infants is high when there is low left ventricular output and hypocarbia but is unaffected by hypotension. Pediatr Res 55:400-405

31. Rosenberg AA 1988 Response of the cerebral circulation to profound hypocarbia in neonatal lambs. Stroke 19:1365-1370

32. Ichord RN, Kirsch JR, Koehler RC, Traytsman RJ 1999 Cerebral anoxia: Experimental view. In: Niedermeyer E, Da Silva FL (eds) Electroencephalography: Basic Principles, Clinical Applications, and Related Fields. Williams and Wilkins, Baltimore, pp 432-444

33. Watanabe K, Hayakawa F, Okumura A 1999 Neonatal EEG: a powerful tool in the assessment of brain damage in preterm infants. Brain Dev 21:361-372

34. Stein SN, Pollock GH 1949 Central inhibitory effects of carbon dioxide II. Proc Soc Exp Biol Med 70:290-291

35. Pollock GH, Stein SN, Gyarfas K 1949 Central inhibitory effects of carbon dioxide III. Proc Soc Exp Biol Med 70:291-292

36. Caspers H, Speckmann EJ, Lehmenkuhler A 1979 Effects of carbon dioxide on cortical field potentials in relation to neuronal activity. In: Speckmann EJ, Caspers H (eds) Origin of Cerebral Potentials. Thieme, Stuttgart, pp 151-163

37. Parfenova H, Shibata M, Zuckerman S, Leffler CW 1994 CO2 and cerebral circulation in newborn pigs: cyclic nucleotides and prostanoids in vasculr regulation. Am J Physiol 266:H1494-H1501

38. Leahy FA, Cates D, MacCallum M, Rigatto H 1980 Effect of CO2 and 100\% O2 on cerebral blood flow in preterm infants. J Appl Physiol 48:468-472

39. Pryds O, Greisen G, Skov LL, Friis-Hansen B 1990 Carbon dioxide-related changes in cerebral blood volume and cerebral blood flow in mechanically ventilated preterm neonates: comparison of near infrared spectrophotometry and 133Xenon clearance. Pediatr Res 27:445-449

40. Hino JK, Short BL, Rais-Bahrami K, Seale WR 2000 Cerebral blood flow and metabolism during and after prolonged hypercapnia in newborn lambs. Crit Care Med 28:3505-3510

41. Eaton DG, Wertheim D, Oozeer R, Dubowitz LM, Dubowitz V 1994 Reversible changes in cerebral electrical activity associated with acidosis in preterm neonates. Acta Pediatr 83:486-492

42. Wyke BD, Graham GR, Hill DW, Nunn JF 1963 Neurophysiological aspects of narcosis produced by inhalation of very high concentrations of carbon dioxide. I Changes in cerebral electrical activity. In: Wyke BD (ed) Brain Function and Metabolic Disorders. Butterworth, London, pp 161-163 
43. Evans N, Kluckow M 1996 Early determinants of right and left ventricular output in ventilated preterm infants. Arch Dis Child Fetal Neonatal Ed 74:F88-F94

44. Cunningham S, Symon AG, Elton RA, Zhu C, McIntosh N 1999 Intra-arterial blood pressure reference ranges, death and morbidity in very low birthweight infants during the first seven days of life. Early Hum Dev 56:151-165

45. Meek JH, Tyszczuk L, Elwell CE, Wyatt JS 1998 Cerebral blood flow increases ove the first three days of life in extremely preterm neonates. Arch Dis Child Feta Neonatal Ed 78:F33-F37

46. Pryds O, Greisen G, Lou H, Friis-Hansen G 1989 Heterogeneity of cerebral vasoreactivity in preterm infants supported by mechanical ventilation. J Pediatr 115:638645
47. Levene MI, Shortland D, Gibson N, Evans DH 1988 Carbon dioxide reactivity of the cerebral circulation in extremely premature infants: effects of postnatal age and indomethacin. Pediatr Res 24:175-179

48. Fenton AC, Woods KL, Evans DH, Levene MI 1992 Cerebrovascular carbon dioxide reactivity and failure of autoregulation in preterm infants. Arch Dis Child 67:835-839

49. Koehler RC, Traystman RJ 1982 Bicarbonate ion modulation of cerebral blood flow during hypoxia and hypercapnia. Am J Physiol 243:H33-H40

50. Kontos HA, Raper AJ, Patterson JL 1977 Analysis of vasoactivity of local pH, $\mathrm{PaCO}_{2}$ and bicarbonate on pial vessels. Stroke 8:358-360

51. Wagerle LC, Kumar SP, Belik J, Delivoria-Papadopoulos M 1988 Blood-brain barrie to hydrogen ion during acute metabolic acidosis in piglets. J Appl Physiol 65:776-781 